\title{
Conformational Study of Human Serum Albumin in Pre-denaturation Temperatures by Differential Scanning Calorimetry, Circular Dichroism and UV Spectroscopy
}

\author{
Mostafa Rezaei-Tavirani ${ }^{1,6, *}$, Seyed Hassan Moghaddamnia ${ }^{2}$, Bijan Ranjbar ${ }^{3}$, \\ Mojtaba Amani ${ }^{4}$ and Sayed-Amir Marashi ${ }^{5}$ \\ ${ }^{1}$ Faculty of Medicine, Medical University of Ilam, Ilam, Iran \\ ${ }^{2}$ Faculty of Paramedical Sciences, Shahid Beheshti University of Medical Sciences and Health Services, Tehran, Iran \\ ${ }^{3}$ Department of Biophysics, Faculty of Science, Tarbiat Modarres University, Tehran, Iran \\ ${ }^{4}$ Department of Biophysics, Institute of Biochemistry and Biophysics, University of Tehran, Tehran, Iran \\ ${ }^{5}$ Department of Biotechnology, University College of Science, University of Tehran, Tehran, Iran \\ ${ }^{6}$ Asre-Novin Institute of Research and Industrial Services, Unit 15, Nariman Building, \\ Kamranyeh Junction, Shahid-Bahonar Ave., Tehran, Iran
}

Received 7 January 2006, Accepted 4 May 2006

\begin{abstract}
Thermal conformational changes of human serum albumin (HSA) in phosphate buffer, $10 \mathrm{mM}$ at $\mathrm{pH}=7$ are investigated using differential scanning calorimetric (DSC), circular dichroism (CD) and UV spectroscopic methods. The results indicate that temperature increment from $25^{\circ} \mathrm{C}$ to $5^{\circ} \mathrm{C}$ induces reversible conformational changes in the structure of HSA. Conformational change of HSA are shown to be a three-step process. Interestingly, melting temperature of the last domain is equal to the maximum value of fever in pathological conditions, i.e. $42^{\circ} \mathrm{C}$. These conformational alterations are accompanied by a mild alteration of secondary structures. Study of HSA-SDS (sodium dodecyl sulphate) interaction at $45^{\circ} \mathrm{C}$ and $35^{\circ} \mathrm{C}$ reveals that SDS affects the HSA structure at least in three steps: the first two steps result in more stabilization and compactness of HSA structure, while the last one induces the unfolding of HSA. Since HSA has a more affinity for $\mathrm{SDS}$ at $45^{\circ} \mathrm{C}$ compared to $35^{\circ} \mathrm{C}$, It is suggested that the net negative charge of HSA is decreased in fever, which results in the decrease of HSA-associated cations and plasma osmolarity, and consequently, heat removal via the increase in urine volume.
\end{abstract}

Keywords: Circular dichroism, Conformational changes, Differential scanning microcalorimetry, HSA, Sodium dodecyl sulphate

\footnotetext{
*To whom correspondence should be addressed.

Tel: 98-21-22815616; Fax: 98-21-22815601

E-mail: rezaei.tavirani@ibb.ut.ac.ir
}

\section{Introduction}

The mechanism by which proteins fold from a structure-free denatured state to their unique biologically active state is an intricate process. This process is even more complex in multidomain proteins where each domain may be able to refold independently and interdomain interactions may affect the overall folding process (Wetlaufer, 1981; Privalov, 1982; Ptitsyn, 1994). The presence of stable intermediate conformations has helped in understanding of protein folding mechanisms (Redfield et al., 1994; Privalov, 1996). Elucidation of the mechanism of protein denaturation is important for understanding of protein stability (Ptitsyn, 1995). Proteins can be denatured in two ways, namely, chemical and thermal (Santoro and Bolen, 1988). Human serum albumin (HSA) has been used as a model protein for protein folding and ligand-binding studies over many decades (Kragh-Hansen, 1981; Dill et al., 1989). HSA is a single chain protein with 585 amino acids, with a molecular weight of $\sim 67,000 \mathrm{Da}$. Serum albumin homologs with very similar properties are found in other mammals. The structure of this protein has been determined by X-ray crystallography of high resolution (Sugio et al., 1999); it includes three homologous domains (I-III) that assemble a heart-shaped molecule. Each domain is formed by two subdomains that possess common structural motifs (Tanford, 1968; Carter and Ho, 1994). HSA has one cysteine residue at position 34 (in domain I) with a free sulfhydryl group (Farruggia and Picó, 1999; Sugio et al., 1999).

HSA plays a special role in transporting metabolites and drugs throughout the vascular system and also in maintaining the $\mathrm{pH}$ and osmotic pressure of plasma (Ikeguchi et al., 1992; 
He and Carter, 1992; Carter and Ho, 1994). Interestingly, HSA structure and dynamics are known to be influenced by a number of factors, like $\mathrm{pH}$, temperature, and binding of different ligands (Brown, 1977).

The thermal denaturation process using differential scanning calorimetric (DSC) method can be described by Eyring and Lumry model (Galisteo et al., 1991):

$$
\text { Native } \leftrightarrows \text { Unfolded reversibly } \rightarrow \text { Unfolded irreversibly }
$$

(scheme 1)

The first stage includes reversible structural alteration on the basis of two-state model, similar to what is described by Pace (1990),

$$
\text { Native (N) } \leftrightarrows \text { Denature (D) }
$$

while the second stage includes irreversible structural alterations. Irreversible structural changes of HSA occur in temperatures above $74^{\circ} \mathrm{C}$ (Kragh-Hansen, 1981). Studies from unfolding of acrylodan-labeled HSA probed by steady-state and timeresolved fluorescence methods have shown that increasing temperature to about $50^{\circ} \mathrm{C}$ is results in reversible separation of domain I and II. Denaturation by heating to $<70^{\circ} \mathrm{C}$ resulted in irreversible unfolding of domain II, while increasing the temperature to $70^{\circ} \mathrm{C}$ or higher resulted in irreversible unfolding of domain I (Flora et al., 1998). The denaturation experiments indicate that unfolding of HSA proceeds by the following scheme:

$$
\mathrm{N} \leftrightarrows \mathrm{E} \rightarrow \mathrm{I} \rightarrow \mathrm{U}
$$

where $\mathrm{N}$ is the native form of the protein, $\mathrm{E}$ is the expanded form, I is an intermediate in which domain II is unfolded but domain I is intact, and finally, $U$ is the unfolded protein. This model is consistent with the previous reports that suggest there is a multi-step unfolding pathway for HSA (Wetzel et al., 1980; Picó, 1997). Scheme 3 shows that unfolding of domain I occurs only when the unfolding of domain II is complete. The U state is not a fully unfolded random coil, but it is rather a partially unfolded state (Shaklai et al., 1984). This is likely the result of unfolding of the pocket containing the free -SH group of Cys34, which enables disulfide bonds to be formed within various domains, and/or the presence of some intramolecular cooperation in the thermal denaturation that act to maintain some degree of structure (Flora et al., 1998).

Studies of unfolding and refolding behavior of HSA using circular dichroism (CD) measurements have indicated that the $\alpha$-helical content of the protein decreases upon thermal denaturation to $75^{\circ} \mathrm{C}$ and not fully recover upon subsequent cooling. In addition, temperature increase of to $75^{\circ} \mathrm{C}$ or above promotes HSA aggregation (Wallevick, 1973).

In the present work, using CD, DSC, and UV spectroscopic methods, we studied the thermal behavior of HSA in a temperature range which corresponds to the reversible denaturation of HSA.

\section{Materials and Methods}

Materials. Human serum albumin was purchased from Sigma and used without defatting. Sodium dodecyl sulphate was also obtained from Sigma. The other substances were of reagent grade and were purchased from Merck. Phosphate buffer $(10 \mathrm{mM}, \mathrm{pH}=7.0)$ was used throughout the study.

Methods. DSC experiment was carried out on a Scal-1 microcalorimeter (Russia); the heating rate was fixed at $1 \mathrm{~K} / \mathrm{min}$. An extra pressure of $1.5 \mathrm{~atm}$ was maintained during all DSC runs to prevent possible degassing of the solutions on heating. The baseline preparation was done by buffer in both sample and reference cells. The concentration of the protein solution was $1 \mathrm{mg} / \mathrm{ml}$ for DSC experiments.

The deconvolution analyses and the fittings were done based on the theory of Privalov and Potekhin (1986), which was integrated in Scal-2 software package (supplied by Scal, Russia). This packege enables the user to determine the native and denatured lines based on excess $C_{p}$ (denoted by $C_{p}^{\text {excess }}$ or $<C_{p}>$ ). Then, the deconvolution of $\left\langle C_{p}\right\rangle$ profile to the corresponding sub-peaks can be done so as to minimize the fitting error. Since a $<C_{p}>$ curve may be deconvoluted in different ways, a convincing deconvolution is a one with the minimum number of sub-peaks, which has also a reasonably low fitting error (typically $<1 \%$ ). In this work, the fitting error was as small as $0.8 \%$.

CD spectra were recorded by a Jasco J-715 spectropolarimeter (Japan). Results are expressed as ellipticity, $[\theta]\left(\right.$ degree $\left.\mathrm{cm}^{2} \mathrm{dmol}^{-1}\right)$, based on a mean amino acid residue weight (MRW). This value was assumed to be $113 \mathrm{Da}$ for HSA. The molar ellipticity was determined as

$$
[\theta]_{\lambda}=(\theta \times 100 \mathrm{MRW} / \mathrm{cl})
$$

where $c$ is the protein concentration in $\mathrm{mM}, l$ is the length of light path in $\mathrm{cm}$ and $\theta$ is the measured ellipticity in degree at a given wavelength. The data were smoothed using the Jasco J-715 software, which includes a fast Fourier-transform noise reduction routine. All experiments were repeated three times. The concentration of the protein solution was $0.5 \mathrm{mg} / \mathrm{ml}$ for $\mathrm{CD}$ experiments. Percentage of secondary structures was calculated with the method of Chen et al. (1972). The $\alpha$-helix content $\left(f_{\mathrm{H}}\right)$ was estimated from the ellipticity value at $222 \mathrm{~nm}\left([\theta]_{222}\right)$.

Spectrophotometeric experiments were performed using a UV 3100 recording spectrophotometer (Shimadzu, Japan). The sample cell contained $0.8 \mathrm{ml}$ of serum albumin solution at a concentration of $0.3 \mathrm{mg} / \mathrm{ml}$ with fixed temperature $\left(25-60^{\circ} \mathrm{C}\right)$ and different fixed concentration of sodium dodecyl sulphate (SDS) ranging from 0.00 to $3.0 \mathrm{mM}$. The reference cell contained buffer and similar concentration of SDS as used in the sample cell, and the absorption of sample cell was recorded at the range of $230 \mathrm{~nm}$ to $330 \mathrm{~nm}$. The absorbance values at $280 \mathrm{~nm}$ for each temperature were illustrated as a function of SDS concentration. 


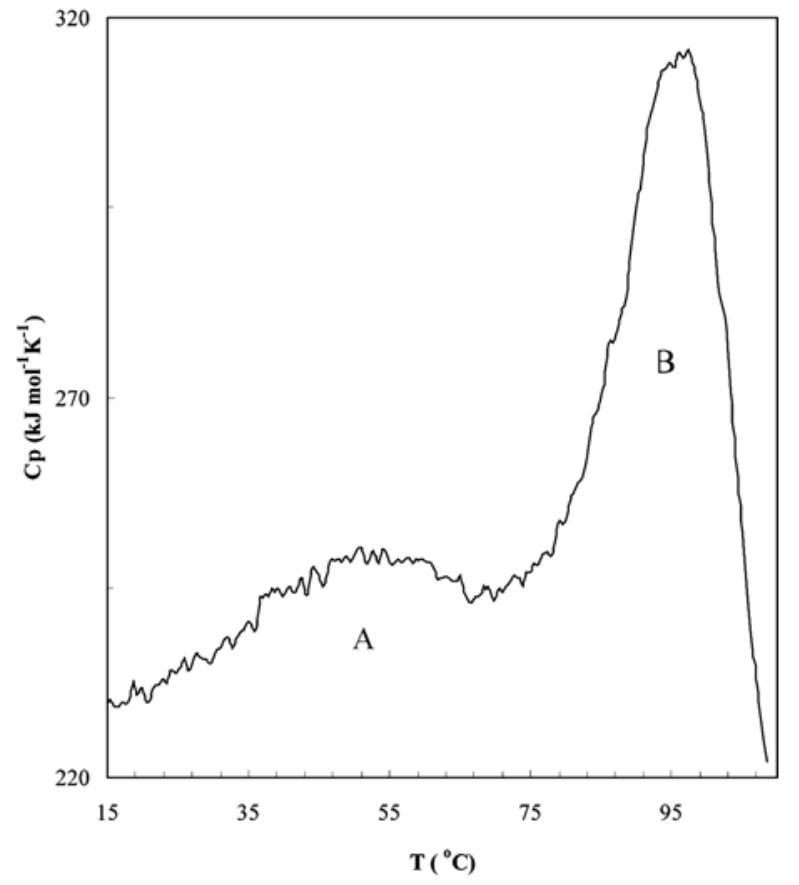

Fig. 1. Differential scanning calorimetry profile of HSA at phosphate buffer $10 \mathrm{mM}, \mathrm{pH}=7$. A and $\mathrm{B}$ are minor and major transitions, respectively.

\section{Results and Discussion}

Figure 1 represents DSC thermogram of HSA in the range of $15-110^{\circ} \mathrm{C}$. DSC profile includes two transitions, $\mathrm{A}$ and $\mathrm{B}$ as depicted in Fig. 1; transition A corresponds to the temperatures below $65^{\circ} \mathrm{C}$ and transition $\mathrm{B}$ occurs at temperatures above $70^{\circ} \mathrm{C}$. Transition A is a minor transition, while transition $\mathrm{B}$ is a major one. The second transition corresponds to the thermal unfolding of HSA via an irreversible process (Saboury et al., 2003), while the first transition is due to the reversible conformational changes that occur before unfolding (Picó, 1997). When the unfolding process is reversible, one can deconvolute its $\left\langle C_{p}>\right.$ curve to its sub-transition constituents to determine its energetic domains.

Deconvolution of $\left\langle C_{p}\right\rangle$ curve for the first transition is represented in Fig. 2. It was found that, with a $<1 \%$ fitting error, it is not possible to deconvolute this $\left\langle C_{p}>\right.$ curve with the assumption of only two sub-transitions. Thus, this transition was deconvoluted with the assumption of three sub-transitions (with a fitting error of $0.8 \%$ ). These three sub-transitions (i, ii and iii), might be related to the links between the three structural domains of HSA (Sugio et al., 1999). The thermodynamic parameters of each sub-transition, such as enthalpy changes and melting temperature values $\left(T_{m}\right)$ are listed in Table 1. The three sub-transitions of HSA as depicted in Fig. 2 and Table 1, are sequential and separated by about $9^{\circ} \mathrm{C}$ considering the $T_{m}$ values. Fascinatingly, $T_{m}$ value of the last sub-transition is $42^{\circ} \mathrm{C}$, which is equal to the maximum degree of fever in body in pathological conditions. The

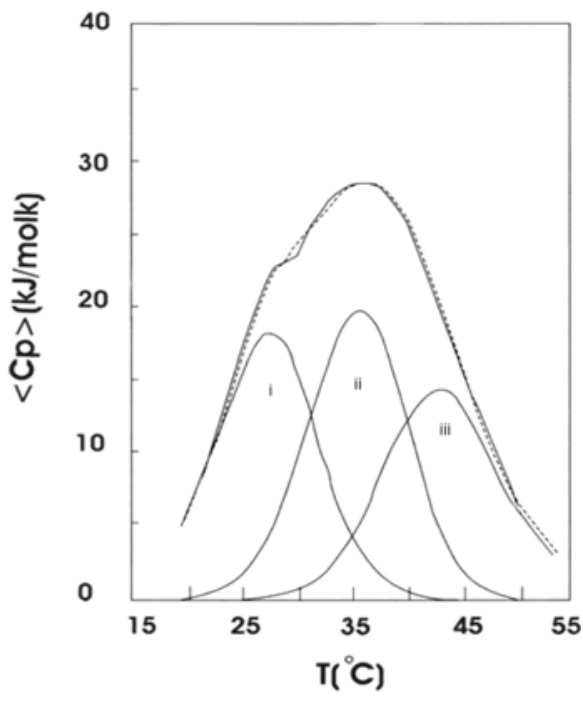

Fig. 2. Deconvolution of excess heat capacity of transition A (see Fig. 1). (-): smoothed experimental curve; (---): calculated curve, as the summation of sub-peaks i-iii.

Table 1. Thermodynamic parameters for three sub-transitions of pre-denaturation transition of HSA corresponding to the subpeaks i-iii in Fig. 2

\begin{tabular}{ccc}
\hline Transition & $\Delta \mathrm{H}, \mathrm{kJmol}^{-1}$ & $T_{m},{ }^{\circ} \mathrm{C}$ \\
\hline i & 248 & 27 \\
ii & 260 & 35 \\
iii & 333 & 42 \\
\hline
\end{tabular}

amount of total enthalpy change of the first transition is equal to $841 \mathrm{~kJ} / \mathrm{mol}$. This transition indicates a relatively mild conformational change in HSA structure, since it results in a reversible denaturation without leading the protein's hydrophobic pockets to be exposed, and thus, leading HSA to aggregation.

Here, we observed a $\left\langle C_{p}>\right.$ curve with three sub-transitions. However, other groups have reported two sub-transitions for the reversible denaturation of HSA (Farruggia et al., 2001). This difference is probably resulted from the fact that Farruggia et al. (2001) used defatted HSA in their study. Such a difference in the DSC thermograms has been reported in case of bovine serum albumin (BSA): $\left\langle C_{p}>\right.$ curve of defatted BSA has two constituents, while undefatted serum albumin is best deconvoluted to three sub-peaks (Michnik, 2003). This phenomenon is presumably a result of asymmetrical distribution of fatty acid binding sites on HSA, (Curry et al., 1998; 1999; Bhattacharya et al., 2000) which results in clearly distinct thermodynamic properties of different structural domains.

It is mentioned that HSA domain separation occurs at temperatures below $50^{\circ} \mathrm{C}$. It is reasonable to assume that this domain separation induces some conformational changes in HSA domains structures. Figure 3 represents CD spectra of HSA in the range of $25-55^{\circ} \mathrm{C}$. Note that the spectra corresponding to $25^{\circ} \mathrm{C}$ and $40^{\circ} \mathrm{C}$ are fairly similar. In addition, the spectra in $45^{\circ} \mathrm{C}$ and $55^{\circ} \mathrm{C}$ are very close to each other. 


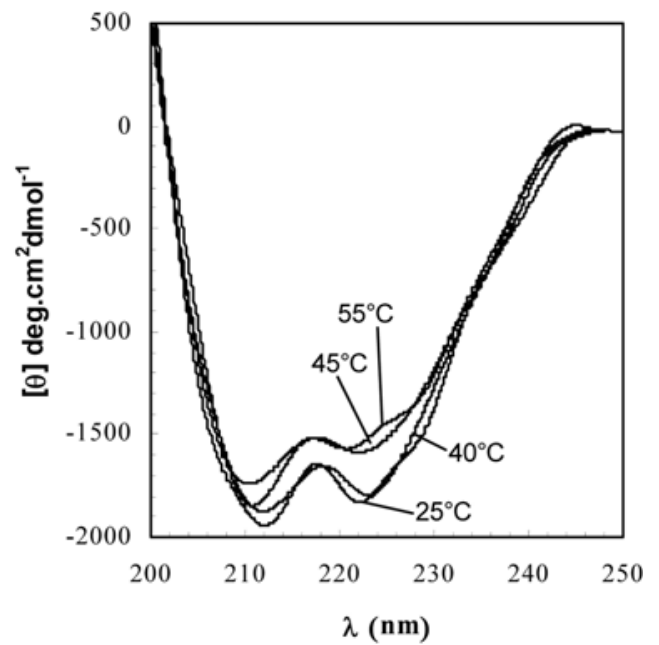

Fig. 3. Far-UV CD spectra of HSA in $25-55^{\circ} \mathrm{C}$.

Table 2. Percentages of HSA $\alpha$-helix structures at $35^{\circ} \mathrm{C}$ and $45^{\circ} \mathrm{C}$

\begin{tabular}{cc}
\hline Temperature, ${ }^{\circ} \mathrm{C}$ & $\alpha$-helix, $\%$ \\
\hline 40 & 67 \\
45 & 64 \\
\hline
\end{tabular}

However, $\mathrm{CD}$ spectrum at $40^{\circ} \mathrm{C}$ shows a relatively considerable difference compared to the spectrum at $45^{\circ} \mathrm{C}$.

Figure 3 indicates that the temperature change from $40^{\circ} \mathrm{C}$ to $45^{\circ} \mathrm{C}$ is a critical event in the course of HSA structural changes. Interestingly, $T_{m}$ of sub-transition iii $\left(42^{\circ} \mathrm{C}\right.$, see Table 1 ), which is obtained from the DSC study, is in the middle of this range. The ratios of HSA $\alpha$-helix structure at $40^{\circ} \mathrm{C}$ and $45^{\circ} \mathrm{C}$ are calculated and illustrated in Table 2; these findings indicate that HSA includes more content of $\alpha$-helix secondary structure (about $3 \%$ ) in $40^{\circ} \mathrm{C}$ relative to $45^{\circ} \mathrm{C}$. The conformational changes of HSA due to the rise of temperature from $40^{\circ} \mathrm{C}$ to $45^{\circ} \mathrm{C}$ is only accompanied by a minor conversion of $\alpha$-helix to other structures; therefore, HSA has a relatively stable conformation in the range of $45-55^{\circ} \mathrm{C}$, as depicted in Fig. 3.

Figure 4 shows $\mathrm{CD}$ spectra in temperatures above $55^{\circ} \mathrm{C}$; note that all spectra show reduction in the $\mathrm{CD}$ parameter at $222 \mathrm{~nm}$ (i.e. $[\theta]_{222 \mathrm{~nm}}$ ). The value of CD parameter at $222 \mathrm{~nm}$ is proportional to the $\alpha$-helix secondary structure; therefore, decrease in this value is an indication of the reduction of the $\alpha$-helix content of the protein. For better resolution, the amount of CD parameter at $222 \mathrm{~nm}$ is plotted as a function of temperature and the plot is compared to a smoothed curve (Fig. 5). Clearly, denaturation occurs in temperatures above $60^{\circ} \mathrm{C}$. Compared to the smoothed curve, there are considerable fluctuations in the $\mathrm{CD}$ parameter at $222 \mathrm{~nm}$ in the predenaturation temperatures; at $40^{\circ} \mathrm{C}$, the proportion of helix structure is greater than the hypothetical smoothed curve, while a reduction in the helix structure occurs as temperature rises to $45^{\circ} \mathrm{C}$. From these observations, it can be concluded that HSA conformation in temperatures above $40^{\circ} \mathrm{C}$ partially loses its $\alpha$-helix structure and thus, HSA is subjected to

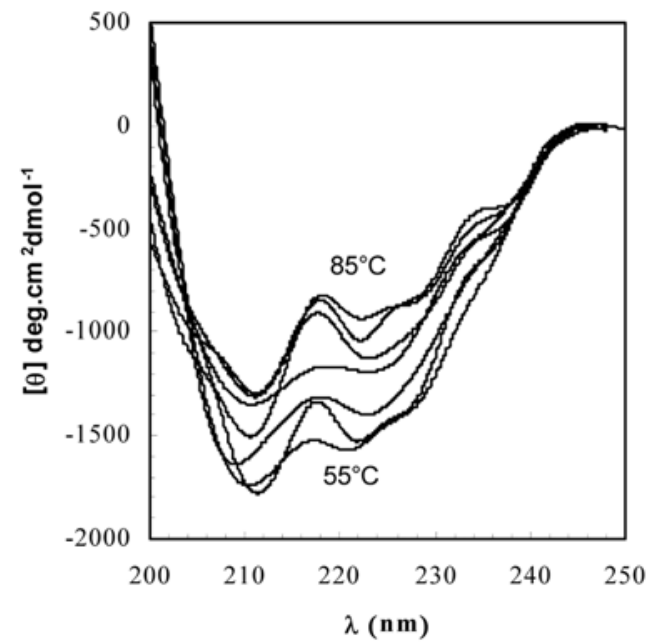

Fig. 4. Far-UV CD spectra of HSA at temperatures above $55^{\circ} \mathrm{C}$.

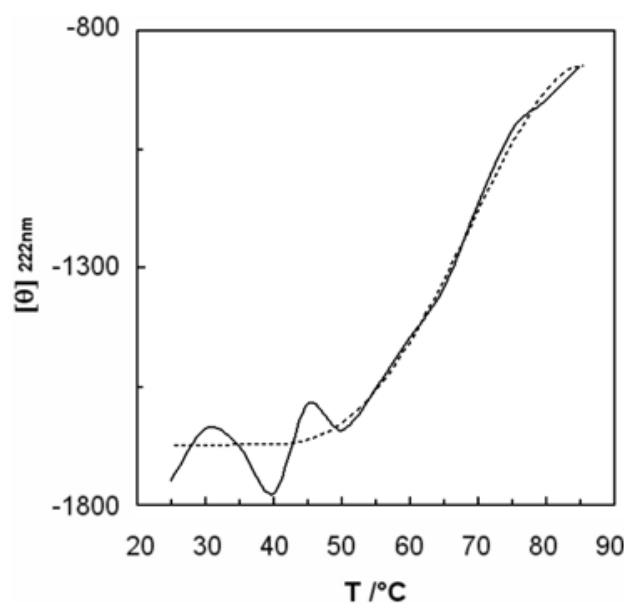

Fig. 5. CD parameter of HSA at $222 \mathrm{~nm}$ as a function of temperature (-). The smoothed curve (---) is added to the plot to facilitate the inspection of fluctuations.

conformational changes compared to its native physiological structure.

Sodium dodecyl sulphate (SDS) is an anionic surfactant with a hydrophobic tail and a negatively charged head; the dual properties of this surfactant have made it a common element of many denaturation studies (Moosavi-Movahedi, 2005). Interaction of serum albumin with SDS has been studied by a variety of techniques (Yamasaki et al., 1992; Giancola et al., 1997; Gelamo and Tabak, 2000; Nielsen et al., 2000; Kragh-Hansen et al., 2001). These studies have revealed that this interaction is a complex process: in low concentrations, SDS induces conformational changes in HSA via electrostatic interactions, with a net stabilizing effect on the structure; in contrast, in the higher concentrations SDS leads to serum albumin denaturation via hydrophobic effects (Giancola et al., 1997). In the present work, SDS as a potential probe and denaturant is used for phase resolution in the course of HSA conformational changes. 


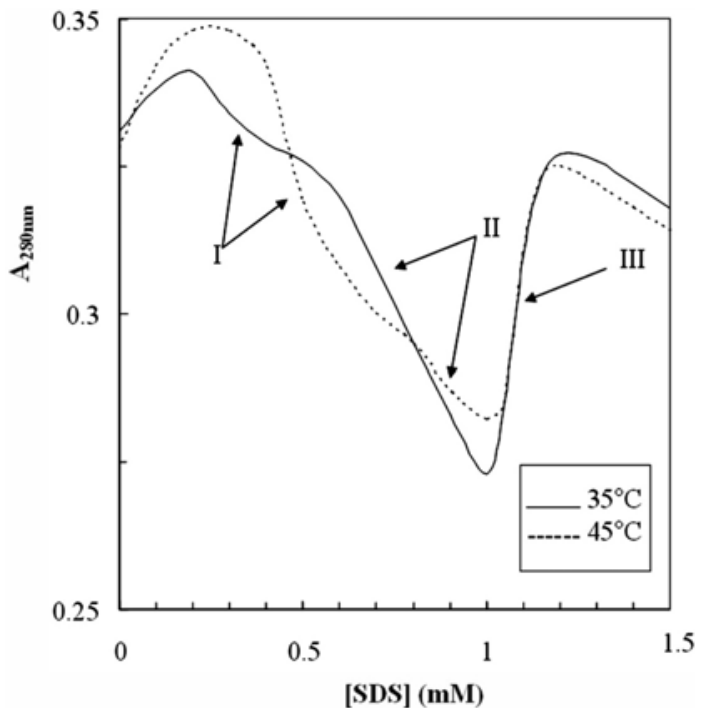

Fig. 6. Absorbance changes at $280 \mathrm{~nm}$ for HSA, including steps I, II and III, as a function of SDS concentration at $35^{\circ} \mathrm{C} \mathrm{(-),}$ and $45^{\circ} \mathrm{C}$ (----).

Figure 6 shows absorbance changes of HSA at $280 \mathrm{~nm}$ as a function of [SDS] (i.e. SDS concentration) in two different pre-denaturation temperatures: $35^{\circ} \mathrm{C}$ and $45^{\circ} \mathrm{C}$. HSA phase transition in the presence of SDS was found to be a three-step process (steps I, II and III in Fig. 6). The two first sigmoidal transitions (I and II) at both temperatures are associated with reduction of absorbance. This implies that HSA structure becomes more stabilized and compact through these transitions, presumably as a result of the interaction of negatively charged SDS heads with several positively charged residues on HSA surface, and its associated cations. In contrast, during the third transition absorbance of HSA is raised. This observation suggests that HSA-SDS interaction in high concentrations of SDS results in the denaturation (unfolding) of HSA, as a result of the hydrophobic denaturation mechanism. Note that transition III is roughly similar in the two temperatures, while the other transitions are totally different.

For better understanding this phenomenon, the sigmoidal transitions I, II and III (for $35^{\circ} \mathrm{C}$ and $45^{\circ} \mathrm{C}$ temperatures) were analyzed by the "two-state model" of Pace (1990). The determination of free energy $\left(\Delta \mathrm{G}^{0}\right)$ as a criterion of conformational stability of a globular "module" (e.g. protein, domain, etc), is based on the assumption that the native module $(\mathrm{N})$ can be directly converted to the denatured state (D) via a reversible process (see scheme 2). Assuming a twostate mechanism for each transition, one can analyze the process by monitoring the changes in the absorbance, and calculate the denatured fraction of protein $\left(\mathrm{F}_{\mathrm{d}}\right)$ as well as the equilibrium constant $(\mathrm{K})$ of the process.

$$
\begin{aligned}
& \mathrm{F}_{\mathrm{d}}=\left(\mathrm{Y}_{\mathrm{N}}-\mathrm{Y}_{\mathrm{Obs}}\right) /\left(\mathrm{Y}_{\mathrm{N}}-\mathrm{Y}_{\mathrm{D}}\right) \\
& \mathrm{K}=\mathrm{F}_{\mathrm{d}} /\left(1-\mathrm{F}_{\mathrm{d}}\right)=\left(\mathrm{Y}_{\mathrm{N}}-\mathrm{Y}_{\mathrm{Obs}}\right) /\left(\mathrm{Y}_{\mathrm{Obs}}-\mathrm{Y}_{\mathrm{D}}\right)
\end{aligned}
$$

where $\mathrm{Y}_{\mathrm{obs}}$ is the observed parameter $\mathrm{Y}$ (which is absorbance

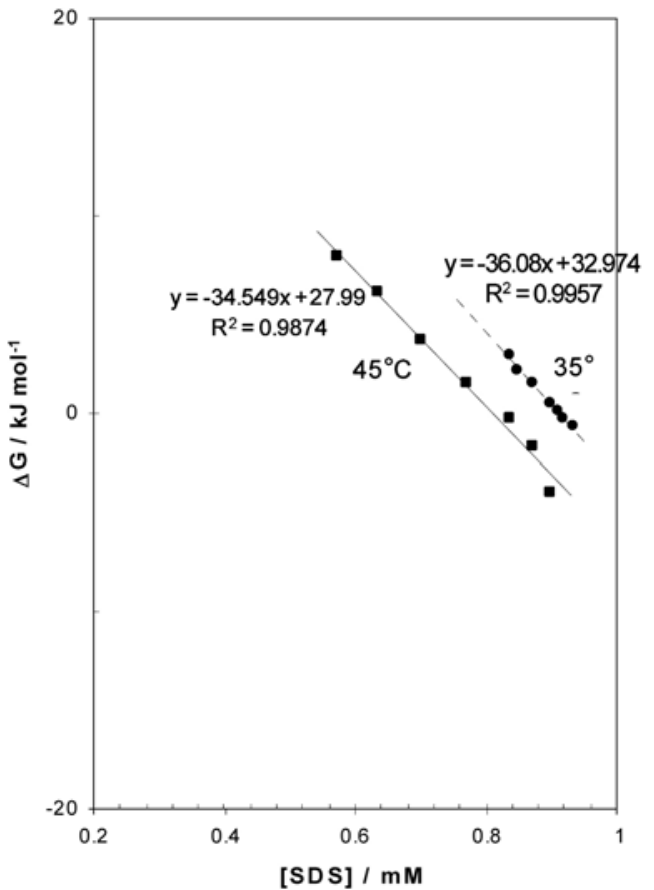

Fig. 7. $\Delta \mathrm{G}^{0}$ curve as a function of [SDS] for HSA transitions I at $35^{\circ} \mathrm{C}(---)$, and $45^{\circ} \mathrm{C}(-)$.

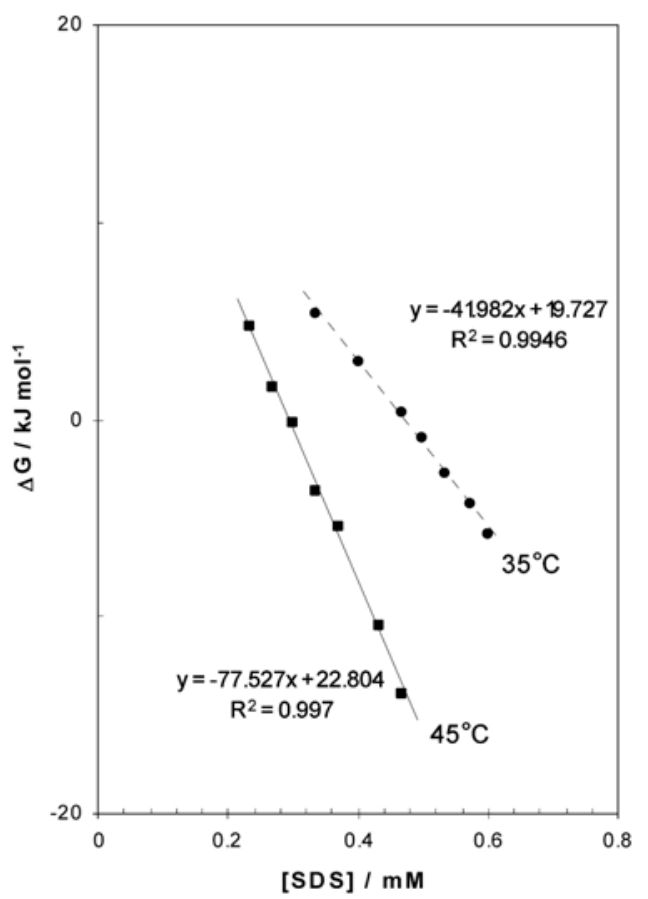

Fig. 8. $\Delta \mathrm{G}^{0}$ curve as a function of [SDS] for HSA transitions II at $35^{\circ} \mathrm{C}(---)$, and $45^{\circ} \mathrm{C}(-)$.

here); $Y_{N}$ and $Y_{D}$ are the values of the $Y$ characteristic of native and fully denatured conformations, respectively. Change in the free energy $\left(\Delta \mathrm{G}^{0}\right)$ can be calculated as:

$$
\Delta \mathrm{G}^{0}=-\mathrm{RT} \operatorname{Ln} \mathrm{K}
$$




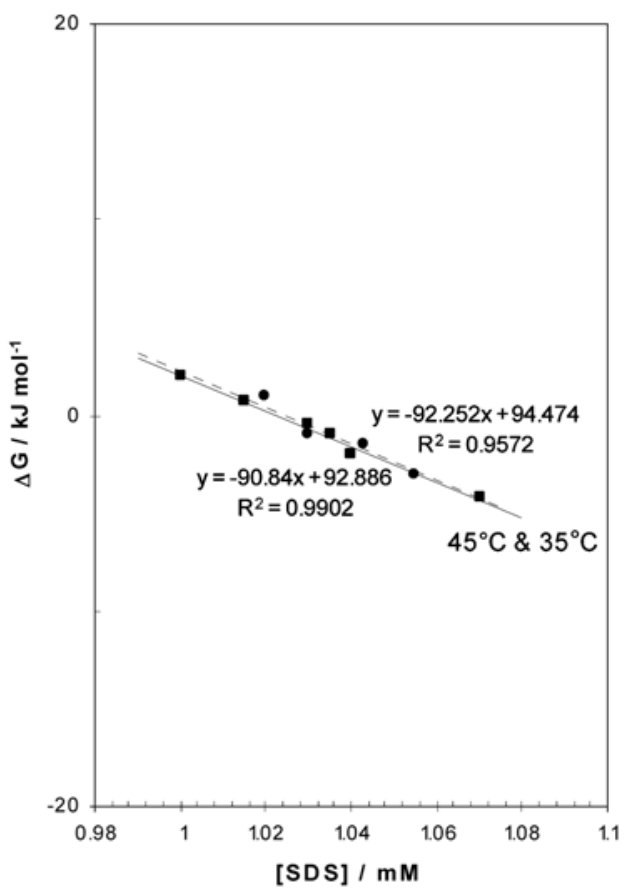

Fig. 9. $\Delta \mathrm{G}^{0}$ curve as a function of [SDS] for HSA transitions III at $35^{\circ} \mathrm{C}(---)$, and $45^{\circ} \mathrm{C}(-)$.

where $\mathrm{R}$ is the universal gas constant and $\mathrm{T}$ is the absolute temperature. The value of $\Delta \mathrm{G}^{0}$ at zero concentration of denaturant $([\mathrm{SDS}]=0)$ is called $\Delta \mathrm{G}_{\mathrm{H} 2 \mathrm{O}}^{0}$, and can be interpreted as the $\Delta \mathrm{G}^{0}$ of native-to-denature transformation in the absence of denaturant. This parameter is routinely used as a measure of protein stability (Moosavi-Movahedi et al., 1994; MoosaviMovahedi et al., 1997; Rezaei-Tavirani et al., 2002; Bougie et al., 2004). One can estimate the value of $\Delta \mathrm{G}_{\mathrm{H} 2 \mathrm{O}}^{0}$ by extrapolating $\Delta \mathrm{G}^{0}$ vs. [SDS] line to zero concentration of SDS. Figures 7-9 show the values of $\Delta \mathrm{G}^{0}$ as a function of [SDS]. For all transitions, $\Delta \mathrm{G}_{\mathrm{H} 2 \mathrm{O}}^{0}$ and $[\mathrm{SDS}]_{1 / 2}$ values are listed in Table 3. $[\mathrm{SDS}]_{1 / 2}$ is the concentration of SDS that causes $50 \%$ phase transition, i.e. where $F_{d}=1 / 2$, and thus, $K=1$ and $\Delta G^{0}=0$. Obviously, the greater the $[\mathrm{SDS}]_{1 / 2}$ value, the more unsusceptible the "module" to SDS-mediated changes.

From Fig. 7 and Table 3, it can be read that at $45^{\circ} \mathrm{C}$, module I is $3.1 \mathrm{~kJ} / \mathrm{mol}$ more stable than this module at $35^{\circ} \mathrm{C}$. At $45^{\circ} \mathrm{C}$, the second module is less stable than its $35^{\circ} \mathrm{C}$ counterpart by $6.0 \mathrm{~kJ} / \mathrm{mol}$, as represented in Fig. 8 and Table 3. It can be calculated that at $35^{\circ} \mathrm{C}$ the first two modules together are more stable than these modules at $45^{\circ} \mathrm{C}$ by $\sim 3 \mathrm{~kJ} / \mathrm{mol}(6.0-3.1=2.9$ $\mathrm{kJ} / \mathrm{mol})$. The values of $[\mathrm{SDS}]_{1 / 2}$ in both modules I and II at $45^{\circ} \mathrm{C}$ are lower than these values at $35^{\circ} \mathrm{C}$, indicating that HSA shows a higher tendency for SDS at $45^{\circ} \mathrm{C}$. The third modules at $45^{\circ} \mathrm{C}$ and $35^{\circ} \mathrm{C}$ are practically the same (see Fig. 9 and Table 3).

Overall, it can be deduced that at $45^{\circ} \mathrm{C}$ HSA structure becomes unstable to some extent. Increase in the SDS affinity of $\mathrm{HSA}$ at $45^{\circ} \mathrm{C}$ relative to $35^{\circ} \mathrm{C}$ suggests that the net negative charge density of HSA surface is somehow suppressed during fever. This might be the result of conformational changes that sequester negatively charged residues and/or expose positively charged residues. It is known that HSA provides $80 \%$ of osmotic pressure of plasma (Carter and Ho, 1994) from which $\sim 30 \%$ is due to the presence of HSA itself and $\sim 50 \%$ is due to the cations (like $\mathrm{Na}^{+}$and $\mathrm{K}^{+}$) associated with the HSA negative surface. Therefore, temperature increase reduces the concentration of the cations around HSA, which can lead to the reduction of blood osmotic pressure. Reduction of blood osmotic pressure under fever conditions can lead to the increment of urine volume, which is a usual condition in fever. The important biological property of water is its high heat capacity, and therefore, excessive exertion of urine accompanies with the removal of heat from body.

Acknowledgments The financial support from the Research Council of the Shahid Beheshti University of Medical Sciences and Health Services is gratefully acknowledged.

\section{References}

Bhattacharya, A. A., Grüne, T. and Curry, S. (2000) Crystallographic analysis reveals common modes of binding of medium and long-chain fatty acids to human serum albumin. $J$. Mol. Biol. 303, 721-732.

Bougie, I., Parent, A. and Bisaillon, M. (2004) Thermodynamics of ligand binding by the yeast mRNA-capping enzyme reveals different modes of binding. Biochem. J. 384, 411-420.

Brown, J. R. (1977) Albumin structure, function and uses, Rosenoer, V. M., Oratz, M., Rothschild, M. A. (eds.), Pergamon Press, Oxford, UK.

Carter, D. C. and Ho, J. X. (1994) Structure of serum albumin. Adv. Protein Chem. 45, 153-203.

Chen, Y. H., Yang, J. T. and Martinez, H. M. (1972) Determination of the secondary structures of proteins by circular dichroism and optical rotatory dispersion. Biochemistry 11, 4120-4131.

Curry, S., Mandelkow, H., Brick, P. and Franks, N. (1998) Crystal structure of human serum albumin complexed with fatty acid reveals an asymmetric distribution of binding sites. Nature

Table 3. The values of $\Delta \mathrm{G}_{\mathrm{H} 2 \mathrm{O}}^{0}$ and $[\mathrm{SDS}]_{1 / 2}$ for transitions I-III of HSA at $35^{\circ} \mathrm{C}$ and $45^{\circ} \mathrm{C}$

\begin{tabular}{ccccc}
\hline Transition & & $\mathrm{I}$ & $\mathrm{II}$ & III \\
\hline \multirow{2}{*}{$\Delta \mathrm{G}_{\mathrm{H} 2 \mathrm{O}}^{0}, \mathrm{~kJ} / \mathrm{mol}$} & $35^{\circ} \mathrm{C}$ & 19.7 & 33.0 & 94 \\
\multirow{2}{*}[\mathrm{SDS}]{$_{1 / 2}, \mathrm{mM}$} & $45^{\circ} \mathrm{C}$ & 22.8 & 28.0 & 93 \\
& $35^{\circ} \mathrm{C}$ & 0.48 & 0.85 & 1.0 \\
\hline
\end{tabular}


Struct. Biol. 5, 827-835.

Curry, S., Brick, P. and Franks, N. P. (1999) Fatty acid binding to human serum albumin: new insights from crystallographic studies. Biochim. Biophys. Acta 1441, 131-140.

Dill, K. A., Alonso, D. O. V. and Hutchinson, K. (1989) Thermal stabilities of globular proteins, Biochemistry 28, 5439-5449.

Farruggia, B. and Picó, G. A. (1999) Thermodynamic features of the chemical and thermal denaturations of human serum albumin. Int. J. Biol. Macromol. 26, 317-323.

Farruggia, B., Rodriguez, F., Rigatuso, R., Fidelio, G. and Picó G. (2001) The participation of human serum albumin domains in chemical and thermal unfolding. J. Protein Chem. 20, 81-89.

Flora, K., Brennan, J. D., Baker, G. A., Doody, M. A and Bright, F. V. (1998) Unfolding of acrylodan-labeled human serum albumin probed by steady-state and time-resolved fluorescence methods. Biophys. J. 75, 1084-1096.

Galisteo, M., Mateo, P. and Sanchez-Ruiz, J. (1991) Kinetic study on the irreversible thermal denaturation of yeast phosphoglycerate kinase. Biochemistry 30, 2061-2066.

Gelamo, E. L. and Tabak, M. (2000) Spectroscopic studies on the interaction of bovine (BSA) and human (HSA) serum albumins with ionic surfactants. Spectrochimica Acta A 56, 2255-2271.

Giancola, C., De Sena, C., Fessas, D., Graziano, G. and Barone, G. (1997) DSC studies on bovine serum albumin denaturation: Effects of ionic strength and SDS concentration. Int. J. Biol. Macromol. 20, 193-204.

He, X. M. and Carter, D. C. (1992) Atomic structure and chemistry of human serum albumin. Nature 358, 209-215.

Ikeguchi, M., Sugai, S., Fujino, M., Sugawara, T. and Kuwajima K. (1992) Contribution of the 6-120 disulfide bond of $\alpha$ lactalbumin to the stabilities of its native and molten globule states. Biochemistry 31, 12695-12700.

Kragh-Hansen, U. (1981) Molecular aspects of ligand binding to serum albumin. Pharmacol. Rev. 33, 17-53.

Kragh-Hansen, U., Hellec, F., de Foresta, B., le Maire, M. and Møller J. V. (2001) Detergents as probes of hydrophobic binding cavities in serum albumin and other water-soluble proteins. Biophys. J. 80, 2898-2911.

Michnik, A. (2003) Thermal stability of bovine serum albumin: DSC study. J. Therm. Anal. Cal. 71, 509-519.

Moosavi-Movahedi, A. A., Naderi, G. A. and Farzami, B. (1994) The denaturation behaviour of calmodulin in sodium n-dodecyl sulphate, dodecyl trimethyl ammonium bromide, guanidine hydrochloride and urea. Thermochimica Acta 239, 61-71.

Moosavi-Movahedi, A. A., Nazari, K. and Saboury, A. A. (1997) Denaturation of horseradish peroxidase with SDS and DTAB, Colloids Surf. B. Biointerfaces 9, 123-130.

Moosavi-Movahedi, A. A. (2005) Thermodynamics of protein denaturation by sodium dodecyl sulfate. J. Iran Chem. Soc. 2, 189-196.

Nielsen, A. D., Borch, K. and Westh, P. (2000) Thermochemistry of the specific binding of $\mathrm{C} 12$ surfactants to bovine serum albumin. Biochim. Biophys. Acta 1479, 321-331.

Pace, C. N. (1986) Determination and analysis of urea and guanidine hydrochloride denaturation curves. Methods Enzymol. 131, 266-280.

Pace, C. N. (1990) Conformational stability of globular proteins. Trends Biochem. Sci. 15, 14-17.

Picó, G. A. (1997) Thermodynamic features of the thermal unfolding of human serum albumin. Int. J. Biol. Macromol. 20, 63-73.

Privalov, P. L. (1982) Stability of proteins. Proteins which do not present a single cooperative system. Adv. Protein Chem. 35, 1104.

Privalov, P. L. (1996) Intermediate states in protein folding. $J$. Mol. Biol. 258, 707-725.

Privalov, P. L. and Potekhin, S. A. (1986) Scanning microcalorimetry in studying temperature-induced changes in proteins. Methods Enzymol. 131, 4-51.

Ptitsyn, O. B. (1994) Kinetic and equilibrium intermediates in protein folding. Protein Eng. 7, 593-596.

Ptitsyn, O. B. (1995) Structures of folding intermediates. Curr. Opin. Struct. Biol. 5, 74-78.

Redfield, C., Smith, R. A. G. and Dobson, C. M. (1994) Structural characterization of a highly-ordered 'molten globule' at low pH. Nat. Struct. Biol. 1, 23-29.

Rezaei-Tavirani, M., Moosavi-Movahedi, A. A., Saboury, A. A., Hakimelahi, G. H., Ranjbar, B. and Housaindokht M. R. (2002) Thermodynamic domain analysis of fresh and incubated human apotransferrin. Thermochimica Acta 383, 103-108.

Saboury, A. A., Hosseini-Kishani, F., Rezaei-Tawirani, M. and Ranjbar, B. (2003) Thermodynamic studies on the interaction of nickel with human serum albumin, Progress Biochem. Biophys. 30, 732-737.

Santoro, M. and Bolen, D. W. (1988) Unfolding free energy changes determined by the linear extrapolation method. 1 . Unfolding of phenylmethanesulfonyl alpha-chymotrypsin using different denaturants. Biochemistry 27, 8063-8068.

Shaklai, N., Garlick, R. L. and Bunn, H. F. (1984) Nonenzymatic glycosylation of human serum albumin alters its conformation and function. J. Biol. Chem. 259, 3812-3817.

Sugio, S., Kashima, A.,. Mochizuki, S., Noda, M. and Kobayashi, K. (1999) Crystal structure of human serum albumin at $2.5 \mathrm{~A}$ resolution. Protein Eng. 12, 439-446.

Tanford, C. (1968) Protein denaturation. Adv. Protein Chem. 23, 121-282.

Wallevik, K. (1973) Reversible denaturation of human serum albumin by $\mathrm{pH}$, temperature, and guanidine hydrochloride followed by optical rotation. J. Biol. Chem. 248, 2650-2655.

Wetlaufer, D. B. (1981) Folding of protein fragments, Adv. Protein Chem. 34, 61-92.

Wetzel, R., Becker, M., Behlke, J., Billwitz, H., Bohm, S., Ebert, B., Hamann, H., Krumbiegel, J. and Lassmann, G. (1980) Temperature behaviour of human serum albumin. Eur. $J$. Biochem. 104, 469-478.

Yamasaki, M., Yano, H. and Aoki, K. (1992) Differential scanning calorimetric studies on bovine serum albumin: III. Effect of sodium dodecyl sulphate. Int. J. Biol. Macromol. 14, 305-312. 